\title{
DEMANDA PEDRO FAUSTO CANALES BERMEJO \\ CONTRA ESPAÑA. INFORME PERICIAL \\ SOBRE VÍCTIMAS DEL FRANQUISMO EN LA \\ SOCIEDAD ESPAÑOLA CONTEMPORÁNEA (15 DE \\ SEPTIEMBRE DE 2012)
}

\author{
DEMAND PEDRO FAUSTO CANALES \\ BERMEJO AGAINST SPAIN. EXPERT COURT \\ REPORT ON VICTIMS OF FRANCHISM IN \\ THE CONTEMPORARY SPANISH SOCIETY \\ (SEPTEMBER $\left.15^{\text {th }}, 2012\right)$
}

\begin{abstract}
Francisco Ferrándiz Martín (CSIC), Juan Antonio Flores Martos (Universidad de Castilla-La Mancha), María García ALONSO (UNED), Julián López García (UNED) y Pedro Tomé MarTín (CSIC)**
\end{abstract}

\begin{abstract}
RESUMEN: El siguiente informe pericial se basa en la experiencia de investigación de los firmantes en exhumaciones de fosas comunes de la Guerra Civil (1936-1939) y la postguerra, en el contexto del "movimiento para la recuperación de la memoria histórica" que está teniendo lugar en España desde el año 2000. Este movimiento ciudadano ha centrado sus demandas en la búsqueda de desaparecidos y ha puesto en marcha un ciclo de exhumaciones de fosas comunes producidas en el contexto bélico y en la dictadura franquista. En este peritaje se utilizan las exhumaciones del siglo XXI como indicadores de la persistencia en el tiempo de las políticas y culturas del miedo
\end{abstract}

\footnotetext{
* Francisco Ferrándiz Martín (Instituto de Lengua, Literatura y Antropología, CSIC) francisco.ferrandiz@cchs.csic.es; Juan Antonio Flores Martos (Universidad de Castilla-La Mancha) juanantonio.flores@uclm.es, María García Alonso (Departamento de Antropología Social y Cultural, UNED), Julián López García (Departamento de Antropología Social y Cultural, UNED) jlopezg@fsof.uned.es y Pedro Tomé Martín (Instituto de Lengua, Literatura y Antropología, CSIC) pedro.tome@cchs.csic.es.
} 
instaladas en la sociedad española, más allá de las profundas transformaciones políticas e institucionales acaecidas en el país tras la muerte de Francisco Franco. Fue presentado como parte de la documentación de la demanda de Fausto Canales contra España el 15 de septiembre de 2012 en el Tribunal Europeo de Derechos Humanos.

Palabras ClaVe: Guerra civil española, informe pericial, memoria histórica.

Aвstract: The following Expert Court Report is based on the experience of research of the signatories in relation to the exhumations of mass graves of the Civil War (1936-1939) and the postwar period, in the context of the "movement for the recovery of historical memory" that is taking place in Spain since 2000. This movement has focused its demands on the search of the missing persons and has launched a cycle of exhumations of mass graves derived from the Civil War and the Dictatorship. In this Report, the exhumations of the 21st century are used as indicators of the persistence over time of the politics and cultures of fear installed in Spanish society, beyond the deep political and institutional transformations that occurred in the country after the death of Francisco Franco. It was presented as part of the documentation of Fausto Canales' Lawsuit against Spain on September 15th, 2012 in the European Court of Human Rights.

Keywords: Spanish Civil War, Expert Court Report, historical memory.

\section{I.- Resumen ejecutivo}

1. El siguiente informe pericial se basa en la experiencia de investigación de los firmantes en relación a las exhumaciones de fosas comunes de la Guerra Civil (1936-1939) y la postguerra, y al conocido como "movimiento para la recuperación de la memoria histórica” que están teniendo lugar en España desde el año 2000, que ha enfatizado sus demandas sobre la suerte de los desaparecidos $\mathrm{y}$ ha puesto en marcha un ciclo de exhumaciones de fosas comunes derivadas de la Guerra Civil (1936-1939) y la dictadura (1939-1975). Algunos de los firmantes tienen un recorrido de más de diez años de investigación, y han dirigido proyectos académicos específicos sobre el tema. Aunque la dictadura del general Francisco Franco acabó en 1975, tuvo lugar un proceso de Transición y España se ha consolidado como un país democrático durante más de tres décadas, puede constatarse que hay aspectos del pasado traumático vinculados a la Guerra Civil y la dictadura que están aún sin resolver. En concreto, los referidos al paradero, identificación y entierro digno de muchos miles de personas desaparecidas en 
acciones represivas de retaguardia durante la guerra por parte del ejército sublevado y grupos paramilitares asociados a él-vinculadas muy directamente con la 'violencia horizontal' ejercida por civiles, vecinos de los municipios e incluso familiares, en un entorno de connivencia, delación y denuncia-. Esta persecución se prolongó, posteriormente, durante todo el régimen dictatorial, con una especial severidad hasta finales de los años cuarenta (Casanova 2002; Rodrigo 2008).

2. Las duras consecuencias sociales, familiares, psicológicas, políticas o económicas en el tejido social en los municipios de esta estructura de delaciones y ejecuciones de civiles, y de las modalidades posteriores de persecución, represión y degradación de los derrotados -incluyendo más ejecuciones, humillaciones públicas de mujeres, encarcelamientos, expropiaciones, depuraciones, multas, marginación social, etcétera-, fueron muy patentes durante el franquismo, y se expresaron en muchos casos en forma de miedo, silencio, sentimientos de culpa y vergüenza, parálisis política y profunda desconfianza institucional. Como argumentaremos con más detalle después, estas consecuencias aún siguen estando en parte presentes a pesar de los más de tres décadas de régimen democrático, especialmente entre las personas mayores que han vivido una parte muy importante de su vida como vencidos o descendientes de vencidos bajo la dictadura militar.

3. Prueba de este déficit o falta de calidad democrática es la emergencia desde el año 2000 de múltiples iniciativas de rescate de la memoria de los vencidos y las víctimas de la guerra, y el desarrollo de un movimiento social de exhumaciones de fosas comunes, en su mayor parte de personas vinculadas o atribuidas al gobierno legítimo derrotado en la Guerra Civil de 1936-1939. Desde el año 2000, se han exhumado más de 270 fosas y se han rescatado en torno a 5.000 cuerpos (Etxeberria 2012). Estas iniciativas de la sociedad civil han tenido como consecuencia la aprobación de una Ley de Memoria Histórica en 2007 en el parlamento español, y la iniciativa judicial ante la Audiencia Nacional, como respuesta a las demandas judiciales de familiares y asociaciones, con consecuencias para el Juez de Instrucción al que le correspondió dicho proceso, quien fue imputado y luego juzgado por delito de prevaricación por su actuación en dicho procedimiento.

4. En este peritaje se usan las exhumaciones del siglo XXI como indicadores de la persistencia en el tiempo de las políticas y culturas del miedo instaladas en la sociedad española durante la Guerra Civil y la dictadura, más allá de las profundas transformaciones políticas e institucionales acaecidas en el país tras la muerte de Francisco Franco. Como antropólogos sociales que trabajamos e investigamos el movimiento para la recuperación de la memoria y las exhumaciones 
promovidas desde él, y con los efectos a corto, medio y largo plazo de las culturas y políticas del miedo, podemos testificar que a día de hoy todavía se perciben con claridad las secuelas traumáticas de la Guerra Civil y el franquismo entre los derrotados y algunos de sus descendientes. Esto ocurre especialmente en aquellas personas de mayor edad que vivieron la Guerra Civil o fueron perseguidas o educadas en una dictadura que les negaba amparo, derechos, legitimidad y dignidad.

5. Estos efectos a largo plazo se refieren por un lado al temor, recelo o dificultad para expresar públicamente los hechos acaecidos y sus consecuencias, y buscar acciones concretas de verdad, justicia y reparación. Estas secuelas son especialmente detectables en los ámbitos rurales, donde están teniendo lugar un buen número de exhumaciones, y donde los descendientes de las personas represaliadas conviven con los descendientes de los responsables de las desapariciones y ejecuciones de civiles y de los enterramientos en fosas comunes. Cabe señalar que hasta el año 2000 no existían apenas asociaciones de ámbito nacional que funcionaran como nodos de información, coordinación y plataformas de apoyo de las víctimas del franquismo respecto a las personas desaparecidas y ejecutadas en la Guerra Civil y la dictadura, los cual es un indicador de las dificultades que ha tenido este colectivo de víctimas para obtener legitimidad social. Las iniciativas en torno a fosas comunes que se produjeron hasta ese momento tuvieron lugar de manera aislada, local y voluntarista al carecer de una estructura asociativa unificadora.

6. Los efectos a largo plazo también se expresan en una desconfianza sostenida hacia el potencial de amparo de las instituciones del Estado, por supuesto durante el franquismo, pero también en democracia, donde la interacción entre este colectivo de víctimas y las instituciones ha resultado muy frecuentemente insatisfactoria. Ejemplo de ello es que, en relación con las fosas comunes de los derrotados en la Guerra Civil, nunca antes se ha indagado sobre los hechos por las instituciones, tampoco hoy en día.

7. Son destacables también las fuertes controversias políticas y mediáticas que se han derivado de este movimiento social de exhumaciones de fosas comunes y de las políticas públicas que se han desarrollado en el país en la última década. Estas controversias, en las que se han vertido acusaciones muy serias de ruptura de la convivencia democrática, han actuado también en muchos casos como inhibidores de la voluntad de muchas personas y colectivos para emprender acciones para conocer el paradero de personas desaparecidas, rescatar a sus deudos de 
fosas comunes y solicitar esquemas institucionales de justicia y reparación cuya responsabilidad en todo caso correspondería al Estado.

\section{II.- Antecedentes históricos}

8. La Guerra Civil española (1936-1939) dejó tras de sí una enorme mortandad. Aparte de la relacionada con los frentes de batalla, hubo un nivel muy alto de represión de retaguardia, que los historiadores cifran en aproximadamente 55.000 personas fusiladas por parte de grupos o agentes políticos que defendían la legalidad republicana, y en torno a 150.000 por parte del ejército sublevado y los grupos paramilitares asociados a él, incluyendo en torno a 20.000 fusilamientos tras la guerra (Juliá, coord. 1999; Rodrigo 2008; Preston 2011). A los que habría que añadir varios miles de personas más muertas en prisiones y campos de concentración tras finalizar la guerra, especialmente entre 1939 y 1942.

9. Como continuación de sus políticas de guerra en la retaguardia, el triunfo de Francisco Franco desembocó en políticas extensivas de represión de los vencidos durante su mandato, que algunos historiadores categorizan como una inversión en terror o una pedagogía de la sangre que permitió, primero, avanzar en el frente militar y, posteriormente, consolidar un régimen dictatorial basado en la gestión del miedo de los derrotados (Rodrigo 2008; Preston 2011). En este contexto, desde el fin de la guerra, tuvo lugar un tratamiento diferencial de las personas ejecutadas en las retaguardias, facilitando exhumaciones y reinhumaciones de los cuerpos reclamados como propios por los vencedores, y abandonando a su suerte a los cadáveres de los vencidos durante décadas (Ferrándiz 2009). Para esta exposición, dentro de la genealogía de exhumaciones de fosas comunes de la Guerra Civil, establecemos cuatro fases: dos promovidas por el Estado franquista (puntos 10 y 11) y otras dos por familiares de Republicanos, con desigual apoyo institucional (puntos 12 y 13).

10. Desde la victoria militar, las víctimas del bando vencedor fueron en buena parte investigadas en una instrucción judicial denominada Causa General, atribuido por Decreto al Ministerio Fiscal en 1940 (Ledesma 2005). Un número todavía por determinar de las personas ejecutadas en la retaguardia republicana fueron localizadas, desenterradas de fosas comunes y cementerios provisionales y reinhumadas bajo el amparo religioso e institucional de la Iglesia y el Estado. Dada la situación de mortandad causada por la guerra y a la limitación de 
recursos económicos, este proceso de exhumación no fue completo. En su totalidad, todos los muertos del bando vencedor, en su calidad de 'caídos' y 'mártires' del Estado franquista y su ideología nacionalcatólica, fueron incorporados a rituales políticos y religiosos, ciclos conmemorativos y proyectos monumentales dentro del paradigma ideológico nacional-católico que era hegemónico en la época (Aguilar 2011; Box 2010); todos tuvieron presencia pública central y políticamente legítima durante el franquismo en los denominados "monumentos a los caídos", que se convirtieron en lugar de obligado homenaje y muchos de los cuales perviven hoy en día.

11. Desde 1959 y hasta 1983 hubo un importante movimiento de cadáveres provenientes de fosas comunes y cementerios de la Guerra Civil de diverso tipo, hacia las criptas del principal monumento funerario del franquismo: el Valle de los Caídos. Estos traslados fueron puestos en marcha mediante una circular a los Gobiernos Civiles firmada por el entonces Ministro de la Gobernación y Presidente del Consejo de las Obras del Monumento Nacional a los Caídos. En total, según las cifras actualmente disponibles, se trasladaron 33.847 cuerpos a este mausoleo. En 1975, Francisco Franco fue enterrado allí junto al altar mayor. Investigaciones recientes certifican que una parte indeterminada de ellos provenían de fosas comunes republicanas, vaciadas y trasladadas sin conocimiento ni permiso de sus familiares. Este dato era desconocido para la opinión pública espańola hasta hace muy pocos años (Ferrándiz 2011).

12. En paralelo a estos procedimientos oficiales franquistas de reubicación de cuerpos de la Guerra Civil, desde el final de la guerra algunas de las fosas republicanas fueron exhumadas u homenajeadas de manera aislada. En una primera fase durante el franquismo (1939-1975), en un proceso sobre el que hay todavía muy pocos datos, toda actividad en torno a las fosas o enterramientos de represaliados republicanos se hizo de manera clandestina y estaba restringi$\mathrm{da}$ a acciones puntuales, con muy pocas excepciones como la de la fosa de La Barranca en La Rioja. En una segunda fase, tras la muerte de Francisco Franco (1975-2000), grupos de familiares abrieron algunas de las fosas republicanas. La investigación sobre estas exhumaciones republicanas previas al año 2000 todavía es fragmentaria. Hasta donde conocemos, la mayor parte tuvieron lugar con escaso o nulo apoyo institucional o técnico. En la mayor parte de los casos estas excavaciones fueron movilizadas por familias o agrupaciones de familiares que utilizaron sus propios medios y recursos económicos. Aunque algunas de ellas tuvieron repercusión en el ámbito local, pocos medios de comunicación nacional o internacional se hicieron eco, excepto por una serie de reportajes de 
la revista de variedades Interviú. Carecemos también de información suficiente para evaluar el impacto que el intento de Golpe de Estado de 1981 tuvo sobre este movimiento de rescate de familiares desaparecidos y sobre la progresión potencial de las reclamaciones de este emergente colectivo de víctimas al Estado, más allá de la importante conmoción social que se produjo y de los temores legítimos de reversión del sistema democrático que condicionaron esos años. Como consecuencia de todo ello, a pesar de su importancia histórica, el impacto social de estas exhumaciones de finales del siglo XX fue limitado y en ningún caso generaron un movimiento social como el que empezó en el año 2000, capaz de coordinar procedimientos, movilizar equipos técnicos, canalizar solicitudes en todo el Estado y, en definitiva, crear las condiciones de posibilidad para articular otro tipo de reclamaciones al Estado.

13. A partir del año 2000 se abre una nueva fase de exhumaciones de fosas republicanas con la excavación de una fosa común de trece personas en Priaranza del Bierzo, en la provincia de León. Desde entonces, se han exhumado más de 270 fosas republicanas, y se han recuperado más de 5.000 cuerpos (Etxeberria 2012). A raíz de esta exhumación se crea la Asociación para la Recuperación de la Memoria Histórica, a la que se añadirán en los años siguientes un número muy elevado de asociaciones de ámbito local, provincial, regional y nacional, destacando entre ellas la Federación de Foros por la Memoria. Este tejido asociativo, unido al impacto mediático de las exhumaciones y a la presión ejercida sobre las administraciones a distintos niveles, desde el local hasta el nacional, ha propiciado las condiciones de posibilidad para que muchas más personas se adhieran a este proceso de reparación. Además, a diferencia de las exhumaciones de fosas republicanas previas, en esta última fase se ha contado paulatinamente con herramientas provenientes del derecho internacional de los derechos humanos y de la justicia transicional para imaginar y diseñar demandas de justicia y reparación (Ferrándiz 2010).

\section{III.- Evaluación de la situación actual de las víctimas del franquismo}

14. Con base a las investigaciones llevadas a cabo en los últimos diez años en el entorno de estas fosas comunes, así como el análisis de su impacto en los diversos ámbitos de la realidad social española del siglo XXI, establecemos los siguientes razonamientos. 
15. Es crucial entender las transformaciones sociales y políticas como procesos que afectan de manera diferencial a los distintos colectivos. Las percepciones sociales sobre la eficacia de los procesos y las transformaciones son también variables, y cambian de manera sustancial de generación a generación. Durante la transición espańola los agentes políticos optaron por un modelo de reconciliación que incluía una Ley de Amnistía y una ética de "echar al olvido" de manera consciente los crímenes del pasado (Juliá 1999). Varias décadas después, de manera más acusada desde principios del siglo XXI, ha emergido paulatinamente una nueva cultura política vinculada a un relevo generacional que pone en cuestión algunos aspectos de este modelo.

16. En efecto, a pesar de las evidentes transformaciones de gran calado en la sociedad española desde la muerte de Franco y la transición a la democracia, existen en la Espańa contemporánea colectivos de víctimas del franquismo para las que sus derechos no han sido satisfechos adecuadamente, y defienden públicamente que este hecho perjudica seriamente a la calidad de la democracia española. A pesar de las múltiples iniciativas desde la muerte de Francisco Franco y la presencia de un movimiento de exhumaciones de ámbito local o regional desde su muerte, como ya hemos apuntado, para muchas de las víctimas del franquismo antes del año 2000 no existían más que marginalmente las condiciones de posibilidad para reclamar derechos y políticas de justicia y reparación, ya sea de manera privada o colectiva. El movimiento para la recuperación de la memoria histórica del siglo XXI ha actuado en la última década como catalizador de buena parte de ese descontento y de las nuevas demandas.

17. La investigación sobre exhumaciones de fosas comunes del siglo XXI ha permitido constatar la persistencia en la actualidad del miedo o el temor asociado a estos enterramientos y a los efectos a largo plazo que el terror político tuvo sobre el tejido social, más específicamente sobre los derrotados en la guerra, durante la dictadura. Los supervivientes y deudos de estos desaparecidos se han educado, han vivido y se han constituido como sujetos y miembros de la sociedad española inmersos durante décadas en lo que algunas corrientes de investigación social denominan un miedo ambiente. Este concepto se refiere a las consecuencias profundas y duraderas que diferentes regímenes basados en la producción y gestión del miedo ejercen sobre el tejido social (Bauman 2003; Becerra 1999). Es posible utilizarlo también, más específicamente, como marco para analizar la experiencia y consecuencias a corto, medio y largo plazo del trauma social y de las culturas del terror en sociedades fracturadas por la violencia, por prácticas habituales del asesinato y desaparición, y por la instauración 
y normalización institucional del silencio y el olvido. En España, como hemos constatado en nuestras investigaciones, las consecuencias a largo plazo que la vida bajo un régimen dictatorial durante décadas tuvo para los sectores sociales que fueron derrotados en la contienda son especialmente apreciables en las personas de mayor edad, que experimentaron los hechos en primera persona y sufrieron directamente los efectos en sus familias y entornos más íntimos, aunque entonces fueran niños. También son muy apreciables en miembros de la generación siguiente -la nacida en los años 40 y principios de los 50, que fueron educados y socializados en ese mismo entorno dictatorial. Durante el franquismo, la propuesta del Estado para las personas vinculadas al bando derrotado en la Guerra Civil eran el sistema penal, la sumisión y el silencio. No existió para ellos ninguna estructura formal ni de reparación, ni de relato, ni de dignificación de los restos de sus familiares ejecutados. En ausencia de ninguna legitimidad pública, el duelo por los desaparecidos se restringía al ámbito familiar o privado, en muchos casos bajo condiciones de sigilo u ocultamiento público. Durante los casi cuarenta años de dictadura, la población fue educada en un marco ideológico que reproducía en los manuales de texto escolares, en los púlpitos, en la ley, en los medios de comunicación o en la propaganda política la versión de la historia de los vencedores en la guerra. Por todos los medios que el Estado pudo desplegar, se inculcó a la sociedad española que no existió represión sino un justo castigo por los crímenes cometidos. Esto provocó en gran parte de la población el convencimiento de que los civiles ejecutados por el bando que resultaría vencedor eran culpables, y por lo tanto responsables, de lo que les ocurrió. En términos generales, ha sido necesario un cambio generacional para que los descendientes de los represaliados republicanos asuman cada vez con mayor convicción que fue la represión y no la justicia la que hizo desaparecer a sus seres queridos, y por lo tanto, que estaban legitimados para rehabilitar su nombre y recuperar sus restos sin avergonzarse de ello.

18. Esta situación ha marcado profundamente varias generaciones de españoles. Aún en las exhumaciones contemporáneas, hemos documentado con frecuencia casos en los que ciertas personas se niegan a hablar de su historia, o la expresan en susurros, evaluando sus potenciales oyentes, o sólo en ámbitos privados. También encontramos casos de personas que, setenta años después de los hechos, no acuden a las exhumaciones por temor a la presión social en sus municipios, a la fractura potencial de ciertas relaciones sociales, o a la tensión en el interior de sus familias Algunas personas no lo han superado y han preferido retirarse de la escena. Otras muestran mucha reticencia a relatar lo que recuerdan o les ha sido trasmitido en el entorno familiar o social más cercano. Para otras 
personas, ha llevado tiempo poder asimilar todas las consecuencias del proceso y poder tomar una posición al respecto. Todo ello atestigua que el miedo y la desconfianza persisten, de manera más acusada en la generación más anciana y en el ámbito rural, y que el proceso político democratizador puesto en marcha en España tras la muerte de Franco todavía no ha llegado plenamente a estos espacios de experiencia social, política y emocional. Este miedo y desconfianza persistentes han tenido sin duda efectos paralizantes en mucha gente. El miedo y el silencio sobre estos hechos del pasado traumático pueden llegar a ser tan fuertes que muchas personas conocedoras de lo que aconteció a familiares directos aún no lo ha podido contar a sus descendientes. Algunos de ellos incluso llegan a enterarse del destino de sus antepasados en el mismo momento de la exhumación (Ferrándiz 2009). Una evidencia de la presencia del miedo que hemos detectado durante nuestras investigaciones de campo reside en los relatos familiares sobre cómo se destruyeron o escondieron evidencias de la memoria de los familiares represaliados. Con frecuencia nos relatan cómo durante la dictadura hicieron desaparecer objetos pertenecientes a sus familiares o cómo en otros casos se han ocultado -en muchas ocasiones hasta la actualidad- fotografías, cartas o pequeños objetos personales por miedo a que el conocimiento público de ellos fuese motivo de represalias o escarnio.

19. Respecto a la pervivencia de la desconfianza y un cierto nivel de temor, es destacable en este sentido que, especialmente en el ámbito rural (aunque también en el urbano), aparte de la presencia aún intimidatoria de las fosas, todavía sigue habiendo símbolos públicos del franquismo visibles en lugares prominentes, incluidos espacios institucionales como ayuntamientos u otros, remanentes de las políticas de memoria excluyentes de la dictadura. Entre ellos, diversas representaciones del yugo y las flechas (símbolo de la Falange), las placas que hay todavía hoy en día en las paredes exteriores de muchas iglesias homenajeando a los "caídos por Dios y por España", o los rastros claros de la victoria militar, la dictadura y muchos de sus prohombres en la denominación de algunas calles principales y en la toponimia. Hay muchos ejemplos. Como muestra de la pervivencia de vestigios del franquismo en la sociedad Española contemporánea, y de la dificultad de su erradicación décadas después de su muerte, cabe señalar la controversia causada en julio de 2012 por la decisión del Juzgado de lo Contencioso Administrativo número 5 de Valencia de que el ayuntamiento de dicha ciudad retire el título de "Alcalde Honorífico" al general Francisco Franco, revocando una decisión contraria del pleno municipal de 29 de julio de 2011. 
20. El proceso de exhumaciones también ha sufrido transformaciones muy destacables en el siglo XXI. Sobre el terreno, el temor a potenciales incidentes que se percibía en los primeros años del siglo se ha ido disipando, y cada vez más gente considera la posibilidad de emprender este proceso, en cualquiera de las modalidades posibles a través de exhumaciones, de investigación y de dignificación. Así, al mismo tiempo que estas excavaciones muestran la persistencia de ciertos niveles de miedo y desconfianza heredados del franquismo, especialmente en personas ancianas en los ámbitos rurales, para otras personas han supuesto una oportunidad para la toma de conciencia sobre su realidad familiar y política. En este sentido, ha sido especialmente la generación de los nietos, y ahora de los bisnietos, la que ha tomado un mayor protagonismo.

21. La Ley 52/2007 "por la que se reconocen y amplían derechos y se establecen medidas en favor de quienes padecieron persecución o violencia durante la Guerra Civil y la Dictadura", conocida como "Ley de Memoria Histórica", establece en su artículo 11 que el Estado "facilitarán a los descendientes directos de las víctimas que así lo soliciten las actividades de indagación, localización e identificación de las personas desaparecidas violentamente durante la Guerra Civil o la represión política posterior y cuyo paradero se ignore". Si bien es cierto que desde el año 2006 hasta el año 2011 el Ministerio de la Presidencia ha convocado ayudas anuales "destinadas a actividades relacionadas con las víctimas de la Guerra Civil y del franquismo", el procedimiento puesto en marcha de acuerdo con los términos de la ley pone en manos de los familiares y asociaciones la responsabilidad última de llevar a cabo y coordinar las investigaciones previas, exhumaciones, estudios de laboratorio, identificaciones y reinhumaciones. Con anterioridad a esta Ley no existía ni siquiera este papel facilitador, excepto en algunas comunidades autónomas que estaban desarrollando sus propias normativas (como es el caso de Cataluña). La citada ley de 2007 y las ayudas institucionales derivadas de ella entre 206 y 2012 han dotado al proceso de búsqueda de personas legitimidad política, y han aportado recursos económicos, pero al mismo tiempo han causado un desamparo ańadido a las víctimas. Al poco tiempo de la llegada de un nuevo gobierno al poder en diciembre de 2011, se produjo el cierre por parte del Consejo de Ministros (el 2 de marzo de 2012) de la Oficina para las Víctimas de la Guerra Civil y la Dictadura -dependiente del Ministerio de Justicia y creada en diciembre de 2008 como desarrollo de la Ley de Memoria 52/2007-. Este cierre, unido a la previsible disminución o eliminación de las subvenciones del Estado, marca un nuevo rumbo institucional en relación a las víctimas del franquismo, habla de la reversibilidad de los escasos avances conseguidos en los últimos años, y aumentará la precariedad de las víctimas. 
22. En las condiciones establecidas por la Ley, a falta de una coordinación centralizada desde las administraciones públicas, son las asociaciones y agrupaciones de familiares las responsables últimas de gestionar todo el proceso. Aunque desde el año 2000 y especialmente desde mediados de la década las principales asociaciones han ido desarrollando procedimientos y consolidando equipos técnicos asociados, en otros casos es reseńable la falta de conocimiento de muchos familiares o agrupaciones de familiares sobre los procedimientos para llevar a cabo de una manera adecuada o satisfactoria este complejo proceso, como lo es el laberinto de trabas legales, burocráticas y administrativas a las que tiene que enfrentarse. Ante el desamparo legal en el que se encuentran, los familiares de los desaparecidos en la Guerra Civil a los que se refiere este informe se ven obligados en muchas ocasiones a hacer por sí mismos o pedir a otros que hagan en su nombre la investigación que permita determinar los hechos más allá de la transmisión oral y saber dónde se encuentran presumiblemente sus deudos. Esto implica que, para activar el proceso, conocer mejor las circunstancias de las desapariciones y posteriores ejecuciones y localizar las fosas comunes, los familiares y sus estructuras de apoyo ad hoc, de mayor o menor solvencia según los casos, tienen que consultar archivos públicos con documentación de carácter histórico y pericial, hacer indagatorias entre vecinos -algunos de ellos hostiles o reticentes- sobre hechos ocurridos y ocultados desde hace décadas, contactar con asociaciones que busquen y faciliten los medios y recursos para realizar la exhumación, solicitar permisos y gestiones ante autoridades municipales o autonómicas que en no pocas ocasiones ponen trabas, llevar a cabo la exhumación, conseguir que algún equipo técnico se comprometa a analizar e identificar hasta donde sea posible los cuerpos exhumados en los laboratorios, y gestionar el regreso y reinhumación de los cuerpos en los municipios. En el extremo de desamparo, hay constancia de casos en los que este proceso ha sido inicialmente asumido por personas de edad avanzada, con insuficiente formación para las responsabilidades contraídas y con poca movilidad, que viven en pueblos alejados muchas veces de los lugares y archivos donde se encuentran las asociaciones, la información y los recursos que precisan.

23. Más allá de las limitaciones de la Ley 52/2007, las reclamaciones de derechos de las víctimas del franquismo vinculadas a los desenterramientos del siglo XXI han coincidido además con el desarrollo y popularización del derecho internacional de los derechos humanos, que ha añadido un nuevo horizonte de interpretación del pasado bajo un prisma de una doble responsabilidad: la del Estado por violación de sus obligaciones internacionales, así como la responsabilidad penal individual, antes inimaginables en España. Respecto al potencial 
de movilización de las víctimas del franquismo desde la muerte de Francisco Franco, es de destacar que el conocimiento y conciencia social de estas herramientas de justicia y reparación es muy reciente en Espańa. Han sido los casos de jurisdicción universal, sobre todo a raíz del caso Pinochet hasta llegar al caso de la Audiencia Nacional que dio lugar al procedimiento penal por prevaricación contra el Juez Instructor, Baltasar Garzón, el que ha permitido a muchas personas y colectivos entender mejor el ámbito transnacional del derecho penal internacional y del derecho internacional relativo a los derechos humanos, y su potencial de aplicación a España (Ferrándiz 2010).

24. La paulatina exposición mediática de los colectivos de víctimas referidos y sus demandas han contribuido decisivamente y de manera progresiva al conocimiento público de su causa en la sociedad espańola contemporánea y en el contexto internacional, $y$ ha abierto nuevos espacios de solidaridad y legitimidad que no existían previamente. Pero al mismo tiempo, las controversias políticas y mediáticas que se han dado entorno a este proceso de recuperación de la memoria histórica han sido, en algunas fases, muy agrias. Un ejemplo del enconamiento de las disputas políticas está en los debates parlamentarios relativos a la discusión y aprobación de la Ley de Memoria histórica, así como cuando el Juzgado Central de Instrucción $\mathrm{N}^{\circ} 5$ de la Audiencia Nacional se declaró competente para investigar las denuncias presentadas por familiares y asociaciones memorialistas. La hemeroteca y los archivos audiovisuales contienen información suficiente sobre el grado de desinformación y agresividad respecto a este proceso en algunos grupos mediáticos, que ha resultado dolorosa para las víctimas. Entre las argumentaciones que han esgrimido en el espacio público están la de guerracivilismo, pretender reabrir viejas heridas y poner en peligro la convivencia, o incluso necrofilia. Así, podemos hablar de que en ciertos momentos se ha producido una crispación sobrevenida desde los discursos políticos y de determinados medios de comunicación que ha dificultado la normalización del proceso y ha podido actuar como inhibidora de iniciativas personales o asociativas respecto a la reclamación de derechos.

\section{Conclusiones}

25. Como consecuencia del tratamiento diferencial de los represaliados en la Guerra Civil, que ha privilegiado históricamente a los asumidos por los vencedores en la contienda (investigados, exhumados en casos, y homenajeados en 
el contexto de una ideología político-religiosa que daba sentido a su muerte y organizaba su duelo público y privado), los descendientes de los vencidos, han sentido históricamente una marginación sistemática que les ha impedido no sólo cerrar el duelo por los desaparecidos y fallecidos sino también, en la mayor parte de las ocasiones y hasta el siglo XXI, la investigación y el acceso a sus restos so pena de generar graves conflictos sociales.

26. Durante la transición española y las primeras décadas de democracia la atención a las desapariciones de civiles en la retaguardia del ejército sublevado fueron escasas, aisladas y provenían fundamentalmente de iniciativas de la sociedad civil, especialmente en el ámbito familiar y municipal. Como ha señalado un influyente historiador español, la actitud respecto al pasado traumático fue la de "echar al olvido" de manera consciente -es decir, una modalidad de "olvido activo"- los crímenes del pasado, en aras de una reconciliación nacional (Juliá 2003). En consecuencia, de manera general, no se daban las condiciones de posibilidad para que los familiares de los desaparecidos promovieran acciones públicas o privadas de investigación sobre las causas de las desapariciones y fusilamientos ni de reparación o dignificación de sus deudos. No ha sido hasta el año 2000 cuando el proceso de búsqueda de este colectivo de desaparecidos ha empezado a consolidarse y las administraciones han empezado a responder antes las demandas de sectores de la sociedad civil con políticas públicas específicas, si bien de manera desigual, fragmentaria e incompleta.

27. La proliferación e impacto mediático de las exhumaciones del siglo XXI en España han sido, junto con el desarrollo de algunas políticas públicas de memoria, las que han producido las condiciones de posibilidad y la legitimidad pública suficiente para que muchos familiares de las víctimas empezaran a romper la desconfianza y el miedo todavía instalados profundamente en determinados ámbitos de la sociedad española, especialmente en lo que se refiere a la represión en los ámbitos rurales, y a las personas socializadas durante el franquismo en un entorno de castigo de sus ideas políticas o su posicionamiento en la contienda y de deslegitimación de su sufrimiento.

28. El proceso sin embargo no ha estado exento de controversias y problemas, alguno de los cuales actúan todavía hoy en día como inhibidores de la movilización de muchos familiares de víctimas. Aunque la Ley 52/2007 forma parte de una estructura política y jurídica de legitimación de las iniciativas que brotan inicialmente de la sociedad civil, el modelo de intervención estatal que establece, en el que el Estado financia (temporalmente) y "facilita" pero se desentiende 
de la coordinación de proceso de investigación, rescate e identificación de las víctimas, ha causado estupor entre los colectivos de víctimas y ha dificultado o imposibilitado la realización de numerosos proyectos. A ello hay que añadir las trabas burocráticas y administrativas, la dificultad de acceso a archivos, la llegada muy tardía e incompleta de protocolos técnicos de garantías, y las duras controversias políticas y mediáticas que ha acompañado a todos los actos relativos a la búsqueda y localización de personas desaparecidas.

29. La socialización de los familiares de los vencidos en un clima de "terror político" y su adoctrinamiento en los principios del Estado franquista, ha propiciado una diferencia generacional significativa respecto de las posibilidades de participar en el movimiento de recuperación de la memoria histórica. Mientras que el movimiento ha sido liderado en el siglo XXI por nietos y ahora bisnietos de las víctimas -con una experiencia periférica del franquismo los más adultos, educados totalmente en democracia los más jóvenes-, a los que se han ańadido algunos miembros de las generaciones anteriores, aquellos que sufrieron más directamente los efectos de la Guerra Civil y los primeros ańos de la dictadura siguen manifestando todavía hoy, particularmente en el medio rural, una fuerte incomodidad antes el desvelamiento público de los hechos acaecidos y las consecuencias que ello puede tener en su entorno social significativo. Las tres décadas de democracia en España no han eliminado en ellos, o lo han hecho de una manera parcial, casi cuarenta años de represión y miedo.

30. Por todo lo establecido en los puntos anteriores, el caso español tiene especial relevancia desde el punto de vista del análisis comparado de la pervivencia del trauma social a través de generaciones. También pone de manifiesto las limitaciones a medio y largo plazo de los pactos políticos de élite -y las políticas de reconciliación asociadas-, como fue el caso de la transición española, para resolver satisfactoriamente algunos temas complejos del pasado, así como para efectuar transformaciones reales y profundas en determinados ámbitos de la realidad social. La aparición y desarrollo posterior de mecanismos internacionales de denuncia y persecución de la impunidad, y la eclosión de la llamada 'justicia transicional', ayudan también a poner en perspectiva histórica las limitaciones del modelo de transición elegido tras la muerte de Francisco Franco para enfrentar con éxito este importante asunto y las repercusiones negativas que ha tenido, ya en el periodo democrático, sobre los colectivos de víctimas a los que se refiere este informe. 


\section{BIBLIOGRAFÍA}

Aguilar, P. (2008): Políticas de la memoria y memorias de la política. Madrid: Alianza.

Bauman, Z. (2003): La modernidad líquida. México D.F.: Fondo de Cultura Económica.

Becerra, O. (1999): "El miedo a la ciudad y la construcción de una identidad", en VVAA, Pensar a Cali: Contextos urbanos. Cali (Colombia): Bellas Artes.

Box, Z. (2010): España, año cero, Madrid: Alianza.

Casanova, J. (2002): "Una dictadura de cuarenta años", en J. Casanova (ed.), Morir, matar, sobrevivir: La violencia en la dictadura de Franco. Barcelona: Crítica, 1-50.

EtxeberRia, F. (2012): “Exhumaciones contemporáneas en Espańa: Las fosas comunes de la Guerra Civil”, Boletin Galego de Medicina Legal e Forense 18: 13-28.

FerRÁNDIZ, F. (2009): "Exhumaciones y relatos de la derrota en la España actual”, Jerónimo Zurita 84: 135-161.

FerRÁndiz, F. (2010): "De las fosas comunes a los derechos humanos: El descubrimiento de las desapariciones forzadas en la España contemporánea", Revista de Antropologia Social 19: 161-189.

Ferrándiz, F. (2011): "Guerras sin fin: Guía para descifrar el Valle de los Caídos en la Espańa contemporánea”, Política y sociedad 48 (3): 481-500.

JuliÁ, S. (2003): "Echar al olvido: Memoria y amnistía en la transición." Claves de Razón Práctica 129: 14-24.

Juliá, S. (coord.) (1999): Victimas de la Guerra Civil. Madrid: Temas de Hoy.

Ledesma, J. L. (2005): "La 'Causa General': Fuente sobre la violencia, la Guerra Civil (y el franquismo)", Spagna Contemporánea 28 (XIV): 203-220.

Preston, P. (2011): El Holocausto español: Odio y exterminio en la Guerra Civil y después. Barcelona: Debate.

Rodrigo, J. (2008): Hasta la raiz: Violencia durante la Guerra Civil y la dictadura franquista. Madrid: Alianza. 


\section{Expertos periciales}

Dr. Francisco Ferrándiz Martín

Dr. Julián López García

Dra. María García Alonso

Dr. Pedro Tomé

Dr. Juan Antonio Flores Martos

\section{Dr. Francisco Ferrándiz Martín}

Doctor en Antropología Social y Cultural por Universidad de California en Berkeley (1996). Actualmente es Científico Titular del Instituto de Lengua, Literatura y Antropología (ILLA) del Centro de Ciencias Humanas y Sociales (CCHS) del Consejo Superior de Investigaciones Científicas (CSIC) desde 2007. Está especializado en antropología de la violencia, con énfasis en investigaciones relacionadas con la memoria, los derechos humanos y el trauma social. Desde 2002 investiga las políticas de la memoria en la Espańa contemporánea, mediante el análisis de las exhumaciones de fosas comunes de la Guerra Civil (1936-1939). Es actualmente Investigador Principal del Proyecto I+D+i Las politicas de la memoria en la España contemporánea: Balance de una década de exhumaciones (CSO 2009-09681, 2010-2012). Ha sido Coordinador de la red europea EDEN (European Doctorate Enhancement on Peace and Conflict Research), financiada por el programa Erasmus de la Comisión Europea. Actualmente es coordinador en el CSIC de la Acción Marie Curie ITN Sustainable Peace Building, financiada por el VII PM europeo (238589). Es autor de Etnografías contemporáneas (2011) y Exhumar la derrota: Fosas comunes del Siglo XXI en España (en prensa), y coeditor de The Emotion and the Truth: Studies in Mass Communication and Conflict (2002), Before Emergency: Conflict Prevention and the Media (2003), Violencias y culturas (2003), Jóvenes sin tregua: Culturas y politicas de la violencia (2005), Multidisciplinary Perspectives on Peace and Conflict Research (2007), Fontanosas 1941-2006: Memorias de carne y hueso (2010), y Down to Earth: The Ethnography of Exhumations (en preparación, Pennsylvania University Press), entre otros. 


\section{Dr. Julián López García}

Julián López García es doctor en Antropología Social por la Universidad Complutense de Madrid. En la actualidad profesor de Antropología en la Universidad de Córdoba (en excedencia) y en la Universidad Nacional de Educación a Distancia donde además es el Coordinador del Grado en Antropología Social y Cultural. Sus investigaciones han tratado sobre simbolismo cultural y sobre cuestiones relativas a las identidades sociales y las representaciones y usos sociales de la violencia y la memoria colectiva, trabajos desarrollados tanto en América Latina (sobre todo en Guatemala, Ecuador y Bolivia) como en España (sobre todo en Extremadura y Ciudad Real). Actualmente dirige el Proyecto I+D+i "Los pueblos indígenas y la modernidad en América Latina" y codirige el proyecto "Todos los nombres de la represión franquista de postguerra en Ciudad Real”, financiado por el Ministerio de la Presidencia del Gobierno de España. Vinculado a dicho proyecto y en general a estudio continuado de la memoria de la represión en Ciudad Real, cabe destacar las siguientes publicaciones: el libro conjunto que ha coordinado con Francisco Ferrándiz: Fontanosas 19412006: Memoria de carne y hueso (2010); junto con Luis Pizarro el libro Historia y memoria del socialismo en Puertollano (2011); y junto a Adela García Muñoz y Jorge Moreno Andrés editor y responsable de la introducción y notas de Nubes de Libertad. Memorias de Nicolas Gonzalez Navas (2012). Es además guionista del documental La importancia de llamarse Avelino Garcia, dirigido por Jorge Moreno Andrés. Ha sido codirector de los cursos de la Universidad de Castilla La Mancha y la Universidad Nacional de Educación a Distancia "Utopía, Revolución y Represión en Abenójar" (Abenojar, 2010) y "La represión de posguerra en Ciudad Real" (Puertollano, 2011).

\section{Dra. María García Alonso}

María García Alonso es profesora del departamento de Antropología Social y Cultural de la UNED, doctora por el mismo departamento y licenciada en Antropología de América (Universidad Complutense, Madrid). Actualmente es subdirectora del Centro de Estudios de Migraciones y Exilios de la UNED. Ha estudiado las relaciones entre la antropología, la historia contemporánea y las practicas territoriales, a través de la memoria del pasado reciente de los diversos actores sociales. Para ello ha realizado trabajo de campo en España sobre las Misiones Pedagógicas (1931-1936) y sobre el proceso de exhumaciones de la guerra civil y su impacto social; en Colombia sobre las repercusiones de la Ley 
de Justicia y Paz; y en Uruguay, sobre la recuperación de la memoria de las instituciones educativas tras la dictadura. Ha sido curadora entre otras de las exposiciones: Las Misiones Pedagógicas (1931-1936) en el Cuartel del Conde Duque (Madrid) y otras ciudades (2006-2007) y Las Misiones Sociopedagógicas entre España y América: México-España-Uruguay (Montevideo, 2009). Miembro fundador del Grupo de Estudios de Antropología Americana, de la Red Internacional de Estudios de Territorio y Cultura (RETEC), de la Sociedad Uruguaya de Historia de la Educación, del Grupo de Investigación de la UNED Migraciones y Exilios en el Mundo Contemporáneo y miembro del Grupo de Investigación Territorialidades de la Universidad de Caldas (Colombia). Es coautora de la propuesta del doctorado en Estudios Territoriales de la Universidad de Caldas y forma parte de su cuerpo docente. Entre sus publicaciones destacan: Tuan nyamok: relatos de la vida de Julian de Zulueta; De los nombres de los niños: miradas sobre la infancia y sus conceptos y los libros colectivos: Las Misiones Pedagógicas en la Segunda República (1931-1936); Antropología de los sentidos: la vista; Según cuerpos: ensayo de un diccionario para uso etnográfico y Pensar el final. La eutanasia: éticas en conflicto.

\section{Dr. Pedro Tomé Martín}

Pedro Tomé Martín, actualmente presidente de la Federación de Asociaciones de Antropología del Estado Español (FAAEE), es Científico Titular del Instituto de Lengua, Literatura y Antropología (ILLA) del Centro de Ciencias Humanas y Sociales (CCHS) del Consejo Superior de Investigaciones Científicas (CSIC) desde 2005. Doctor en Filosofía y CC. de la Educación por la Universidad de Salamanca (1995), ha sido profesor de antropología social en la Universidad de Salamanca, de la que fue secretario del Departamento de Psicología Social y Antropología durante seis años, y de la Universidad Nacional de Educación a Distancia. Experto conocedor del medio rural de la Comunidad Autónoma de Castilla y León, ha investigado prolijamente las relaciones entre naturaleza y cultura tanto en dicha Comunidad Autónoma como en México. Actualmente es investigador de proyecto del Plan Nacional de I+D+i (2009-2012) llamado "'El retorno a la tierra'. Problemas, estrategias y dinámicas de la neo-ruralidad". Autor de varios libros y artículos sobre las condiciones de vida de los agricultores y ganaderos castellanos y leoneses, su última obra, conjuntamente con Luis Díaz y Óscar Fernández, lleva por título Lugares, Tiempos Memorias (2011). 


\section{Dr. Juan Antonio Flores Martos}

Es Doctor en Antropología Social por la Universidad Complutense de Madrid. En la actualidad es Profesor Contratado Doctor en Antropología Social de la Facultad de Ciencias Sociales de Talavera de la Reina, en la Universidad de Castilla-La Mancha. Es miembro del "Grupo de Etnografía y Estudios Sociales Aplicados" (Cuenca) y de la Red Internacional de investigación "Expresiones y representaciones de la violencia en Latinoamérica" (Universidad de los Andes, Mérida, Venezuela). Ha sido designado Investigador Titular en 2012 de la Cátedra Gonzalo Aguirre Beltrán por la Comisión Binstitucional CIESAS-Golfo/ Universidad Veracruzana (México). Dirigió como investigador principal el proyecto "Ritos del Ciclo de vida en la Región (1901-2009): un patrimonio etnológico castellanomanchego entre el olvido, la continuidad y la transformación" (2009). Entre sus líneas de investigación destacan la investigación de las violencias cotidianas y del trauma cultural, las culturas del miedo y la antropología de la muerte. Sus últimas publicaciones en este campo han sido Hacia una teoría cultural del trauma y la violencia cotidianas en el puerto de Veracruz (México) (2005), Etnografias de la muerte y las culturas en América Latina (2007), Violencias en la carne, emociones y "cuerpos domésticos en Veracruz, México" (2011) y "Explorando los miedos en la enseñanza de la sociología y la antropología” (2011). Ha escrito el prólogo del libro "La Sierra contra Franco. La lucha guerrillera de Chaqueta Larga y El Manco en las sierras del Centro de España" de Benito Díaz y Juan Pedro Esteban Palmero (Tiempo de Cerezas Ediciones, Madrid).

Madrid, 15 de septiembre de 2012

Recibido: 29/10/2019

Aceptado: 7/12/2019

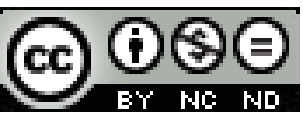

ENDOXA está bajo una licencia de Creative Commons Reconocimiento-NoComercial-SinObraDerivada 4.0 Internacional 